\title{
Simulation of Methane Gas Production Process from Animal Waste in a Discontinuous Bioreactor
}

\author{
Nima Norouzi ${ }^{1}(\mathbb{D})$, Hossein Khajehpour ${ }^{2, *(\mathbb{D})}$ \\ 1 Energy and Physics Department, Amirkabir University of Technology, 424 Hafez Ave. Tehran, Iran; nima1376@aut.ac.ir \\ (N.N.); \\ 2 Energy Department, Sharif University of Technology, Ostad Moein Tehran, Iran, khajeh-pour@energy.sharif.edu (H.K.); \\ * Correspondence: hkhajehpour2020@gmail.com (H.K.);
}

Scopus Author ID 57192684261

Received: 18.01.2021; Revised: 20.02.2021; Accepted: 24.02.2021; Published: 1.03.2021

\begin{abstract}
Due to the importance of environmental protection and the need to use new energy and alternative to conventional fuels, renewable energy has received much attention. Due to this necessity, a discontinuous bioreactor producing methane gas from animal waste has been modeled and simulated in this research. Monod kinetics was used to express the relationship between the growth rate of microorganisms and substrate concentration. The fourth-order Rong Kuta numerical method solved the substrate consumption and production of microorganisms and methane gas. The effect of the initial concentration of microorganisms on methane production has also been investigated. The initial concentrations of substrate and microorganisms are $74.51 \mathrm{~g} / \mathrm{L}$ and $61.1 \mathrm{~g} / \mathrm{L}$, respectively. The results of this study showed that the mathematical model deviates about $53.8 \%$ from the laboratory data. According to the presented model, the amount of methane produced after 70 days is equal to $29.10 \mathrm{~g} / \mathrm{L}$. The decomposition rate of the substrate and methane gas production depends on the substrate's residence time. Increasing the initial concentration of microorganisms produces methane gas in less time. The amount of methane produced is independent of the initial concentration of microorganisms. The model presented in this study can predict the time required to perform the reaction, optimal bioreactor performance, design of relevant process equipment, and increase the scale of equipment, such as storage tank and proper control to produce high purity methane more volume. Suitable in bioreactors.
\end{abstract}

Keywords: anaerobic fermentation; discontinuous bioreactor; mathematical modeling; methane production.

(0) 2021 by the authors. This article is an open-access article distributed under the Creative Commons Attribution (CC BY) license (https://creativecommons.org/licenses/by/4.0/).

\section{Introduction}

Today, one of the main problems of all countries globally, especially developing countries, is energy. Fueling remote villages is very difficult and costly even in a country like Iran, which has rich energy resources. Therefore, other energy production methods that do not have the disadvantages of conventional methods have become commonplace worldwide. One of these methods is energy production from biomass [1]. One of the technologies for converting biomass to energy is biochemical processes. These processes are divided into anaerobic, aerobic, and alcoholic fermentation of biomass. Biogas [2] is obtained by anaerobic fermentation of biomass [1]. In the process of anaerobic fermentation, organic matter [3] is soluble and absorbable by microorganisms by chemical reaction, and they are used to perform their vital activities [2]. Biogas is a colorless, almost odorless, flammable gas, a significant 
percentage of which is methane. The composition of biogas is shown in Table 1. According to Table (1), more than half of the biogas composition is methane. This shows the importance of biogas as a new fuel and energy source.

Table 1. Biogas composition.

\begin{tabular}{l|c|c} 
Gas name & Percentage composition & Formula \\
\hline Methane & 55 to 75 & $\mathrm{CH}_{4}$ \\
\hline carbon dioxide & 35 to 45 & $\mathrm{CO}_{2}$ \\
\hline Nitrogen & 0 to 1 & $\mathrm{~N}_{2}$ \\
\hline Hydrogen & 0 to 1 & $\mathrm{H}_{2}$ \\
\hline Hydrogen sulfide & 1 to 2 & $\mathrm{H}_{2} \mathrm{~S}$ \\
\hline Oxygen & Insignificant amounts & $\mathrm{O}_{2}$ \\
\hline carbon monoxide & Insignificant amounts & $\mathrm{CO}$
\end{tabular}

Anaerobic fermentation, also known as biological methane generation, is a process that occurs naturally in landfills, sewers, and swamps [2,3]. The main sources for biogas production are animal waste, sewage, municipal and industrial wastes, agricultural wastes such as rice bran, sugar beet, etc. $[4,5]$. Since all the mentioned resources are produced in large quantities in our country, there is a potential ability to produce biogas. Today, in many large and industrialized European countries and countries like Canada, biogas generate electricity and generate heat on a small scale $[6,7]$. Other benefits of biogas include economic efficiency, low sludge production, removal of minerals [3, 8], removing odors from waste materials [3], and reducing greenhouse gas emissions. In 1952, Baswell and Müller [6] proposed that if the feed input to the reactor was known to be the organic matter with a combined composition, the amount of methane and carbon dioxide produced could be calculated with a maximum error of $5 \%$ [8-12].

$$
C_{n} H_{a} O_{b}+\left[n-\frac{a}{2}-\frac{b}{2}\right] H_{2} O \rightarrow\left[\frac{n}{2}-\frac{a}{8}+\frac{b}{4}\right] C O_{2}+\left[\frac{n}{2}+\frac{a}{8}-\frac{b}{4}\right] C H_{4}
$$

In 1976, Boyle [7] modified equation (1) and proposed the following reaction, in which he determined the amount of ammonia and hydrogen sulfide production by considering nitrogen and sulfur [13].

$$
\mathrm{C}_{n} \mathrm{H}_{h} \mathrm{O}_{n} \mathrm{~S}_{\mathrm{s}}+y \mathrm{H}_{2} \mathrm{O} \rightarrow x \mathrm{CH}_{4}+n \mathrm{NH}_{3}+\mathrm{sH}_{2} \mathrm{~S}+(\mathrm{c}-x) \mathrm{CO}_{2}
$$

where the coefficients are defined as follows:

$$
\begin{aligned}
& x=\frac{1}{8}(4 c+h-2 o-3 n-2 s) \\
& y=\frac{1}{4}(4 c+h-2 o-3 n-3 s)
\end{aligned}
$$

Baserga [8] in 1998 divided the organic matter into three categories of carbohydrates, fats, and proteins and determined the product of gas production and molar fraction of methane for these compounds separately [12]. Kimmer and Schilcher's [9] research is based on the Baserga model. They improved the Baserga model by considering the decomposition rate's dependence on the substrate type [14]. Amun et al. [10] also used organic matter as a reference [14] to estimate the energy content of methane from materials such as cereals and corn [15]. The Kimmer and Schilcher model is suitable for animal substrates, and the Amun et al. model is suitable for plant substrates. Due to the need to replace fossil fuels with new sources, many studies have been conducted to increase biogas production and purity of methane gas. In a study, it was shown that $\mathrm{pH}$ control is very effective on methane production. By controlling the $\mathrm{pH}$, methane production's efficiency is about 7.6 times higher than the $\mathrm{pH}$ of the anaerobic 
digestion process [16]. The organic acids produced in the digestion process lead to severe acidification [11] of the environment and prevent methane gas production. The effect of nanoparticles on biogas production has also been investigated. The results show that the use of nickel nanoparticles will increase methane production by 2.17 times compared to the state without nanoparticles [9].

Limited research has been done in the field of modeling and simulation of biogas production reactors. Zhou et al. [12] in 2011 presented their model for substrates that are agricultural wastes in a stable laboratory fermentation and found that their model was well adapted to laboratory data and could be used to predict the performance of agricultural biogas production units. In 2011, Lee et al. [13] modeled a biogas reactor to produce fats, oils, greases, and kitchen waste. The results of their model showed that cosobestra significantly reduces the delay stage of organic biodegradation. They found that the use of waste generated in kitchens, fats, and oils increased methane gas production [6]. Grader et al. [14] investigated the trend of methane production efficiency during corn fermentation. They provided a relationship between methane production efficiency and the chemical composition and quality of forage used [7]. Beba and Atley found that by modeling a discontinuous biogas production reactor from agricultural waste, the contusion model has the best fit between growth rate and substrate decomposition [13]. Modeling of semi-continuous biogas production reactor from municipal waste and waste [17], biogas production from shrimp lake sediments using artificial intelligence [18], and discontinuous and continuous reactors for biogas production from olive pomace [19] have also been studied.

Given the human need for renewable energy sources, research in this area is essential. According to the raw material studies, most previous studies include agricultural waste, plant waste, municipal waste, and wastewater. Due to the importance of animal waste in biogas production [20] in this paper, a discontinuous methane gas bioreactor has been simulated using the Monod model. The effect of changes in the concentration of input microorganisms on the consumption of substrate and crop production has also been investigated. The model can predict the time required to perform the reaction, optimal performance, equipment design, equipment scales, storage tanks, and proper control over bioreactors.

\section{Materials and Methods}

In the present paper, a continuous biogas production reactor from animal waste is modeled and simulated. To determine the modeling's accuracy, kinetic parameters and laboratory results in reference [19] have been used. The Monod model has also been used to establish the relationship between microorganisms' production rate and the substrate's consumption rate $[14,17]$.

In modeling a discontinuous biogas production reactor, the assumptions considered are: Process 1 . is performed at a constant volume. 2. The reaction medium's temperature and $\mathrm{pH}$ are constant and 35 and $7{ }^{\circ} \mathrm{C}$, respectively [19, 20]. 3. Volatile solids [15] are converted to biogas. 4. The rate of loss of volatile solids is proportional to biogas production. 5 . Simultaneously with the consumption of the substrate in the biogas reactor is produced.

Factors such as the growth of microorganisms, substrate decomposition, and product formation affect biogas production. In the discontinuous biogas production process, the substrate decomposition rate and biogas production depend on the input substrate's residence time to the reactor.

The general mass balance for microorganisms in a discontinuous reactor is as follows: 


$$
\frac{d[X]}{d t}=\mu_{n e t}[X]
$$

$\mathrm{X}$ is the concentration of microorganisms, $\mu_{\mathrm{net}}$ of microorganisms' net growth rate, and $t$ time. The net growth rate of microorganisms shown in equation (6) is defined as the difference between the microorganisms produced and the killed microorganisms.

$$
\mu_{n e t}=\mu-K_{d}
$$

where $\mu$ is the growth rate of microorganisms, and $K_{d}$ is the mortality rate [16] of microorganisms are from Equations (5) and (6). The basis for modeling the growth kinetics of bacteria is derived from two German scientists named Michael and Menten [17]. Their model was proposed in 1913 and stated that enzymatic activity depends on the concentration of the substrate. Like the Michael-Menten model, Monod showed a nonlinear relationship between microorganisms' growth rate and the substrate concentration. Equation (7) shows the Monod model.

$$
\mu=\frac{\mu_{\max }[S]}{K_{S}+[S]}
$$

where $\mu_{\max }$ is the maximum growth rate for microorganisms, $\mathrm{K}_{\mathrm{s}}$ is the substrate concentration, and $\mathrm{Ks}$ is the semi-saturation constant. The specific growth rate of microorganisms is a function of substrate concentration and other environmental conditions such as inhibitors, $\mathrm{pH}$, and temperature $[14,19]$. In the following years, with the Monod model's completion, more complete models were suitable for complex substrates and heterogeneous environments [14, 15]. Monod model has high accuracy for pure culture media as well as simple substrates. This model is for homogeneous environments and is not suitable for inhomogeneous environments and complex substrates [14]. Since in the present paper, biogas production from animal waste has been studied, and animal waste is considered a simple substrate, so the Monod model has been used in the simulations. By simplifying equation (5) and using Equations (6) and (7) in it, finally, the changes in the concentration of microorganisms in the discontinuous reactor are in the form of equation (8).

$$
\frac{d[X]}{d t}=\left(\frac{\mu_{\max }[S]}{K_{s}+[S]}-K_{d}\right)[X]
$$

The general mass balance of the substrate for discontinuous processes is in equation (9).

$$
\frac{d[S]}{d t}=-\frac{\mu[X]}{Y_{x i s}}
$$

The production efficiency of microorganisms is defined as the ratio of microorganisms produced to the substrate consumed; therefore, microorganisms' production efficiency can be written as Equation (10) [14].

$$
Y_{x i s}=\frac{[X]-\left[X_{0}\right]}{\left[S_{0}\right]-[S]}
$$


The subtitle o means the initial concentration, assuming that methane gas is produced simultaneously as the substrate is consumed; the equation for changes in the concentration of methane gas produced in the discontinuous reactor is as follows [14].

$$
\frac{d[P]}{d t}=Y_{P} \mu[X]
$$

where $\mathrm{p}$ is the concentration of methane gas, and the $\mathrm{Y}_{\mathrm{p}}$ is the efficiency of its production. To determine the amount of methane produced in the reactor, Equations (8), (9), and (11) must be solved simultaneously. These equations are solved using the quadratic Rang Kota method in Matlab 2016b software. The simulation results are compared with the reference laboratory results [21]. The information used in the simulation is presented in Table 2.

Table 2. Required kinetic information [21].

\begin{tabular}{c|c|c|c|c|c|c} 
Parameters & $\mathrm{Y}_{\text {xis }}$ & $\mathrm{K}_{\mathrm{s}}$ & $\mathrm{X}_{0}$ & $\mathrm{~S}_{0}$ & $\mu_{\max }$ & $\mathrm{Y}_{\mathrm{p}}$ \\
\hline Value & 0.226 & $57.24 \mathrm{~g} / \mathrm{L}$ & $61.1 \mathrm{~g} / \mathrm{L}$ & $74.51 \mathrm{~g} / \mathrm{L}$ & 0.1085 day $^{-1}$ & 41.11
\end{tabular}

\section{Results and Discussion}

The simulation is based on the input substrate concentration of $74.51 \mathrm{~g} / \mathrm{L}$. Table 3 shows the ratio of components in the substrate used [20].

Table 3. Components weight fraction in the substrate used in the production of biogas [20].

\begin{tabular}{l|l} 
Type of experiment & $\mathbf{\%} \mathbf{w} / \mathbf{w}$ \\
\hline Humidity & 83.91 \\
\hline Total solids & 16.09 \\
\hline Carbon present in all solids & 40.70 \\
\hline Nitrogen present in all solids & 2.90 \\
\hline Organic volatile solids (dry based) & 81.52
\end{tabular}

The Monod model is used in the simulations. The Monod model has good accuracy for simple substrates. Figure 1 shows the changes in substrate concentration over time. As time goes on, the input substrate decomposes, thus providing the energy needed to produce, grow, and survive microorganisms. According to Figure 1, the substrate concentration reaches zero after about 70 days.

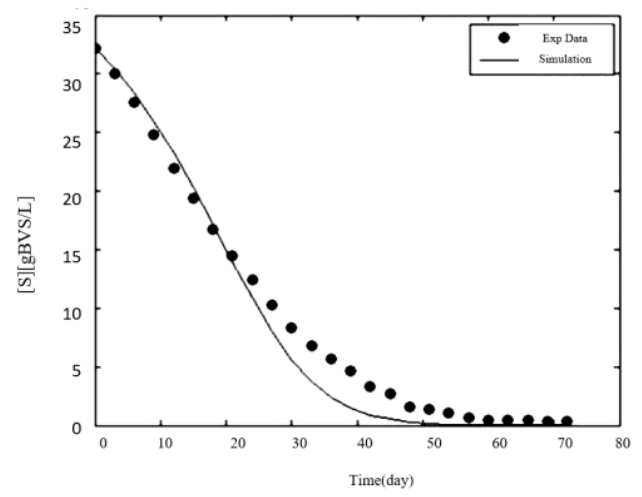

Figure 1. Variation of substrate concentration with time.

Figure 2 shows the changes in the concentration of microorganisms over time. With the increase of the input substrate's time and consumption, microorganisms start to grow and multiply until they reach a constant value with decreasing concentration of the substrate and 
enter the stage of death with its complete consumption. Figures 1 and 2 show that at the same time, with the complete consumption of the substrate, the production of microorganisms also stops and reaches a constant value. Figure 3 shows the changes in methane gas concentration produced over time. As shown in Figure 3, with increasing time, methane gas production also increases until the substrate's production reaches a certain amount and remains constant.

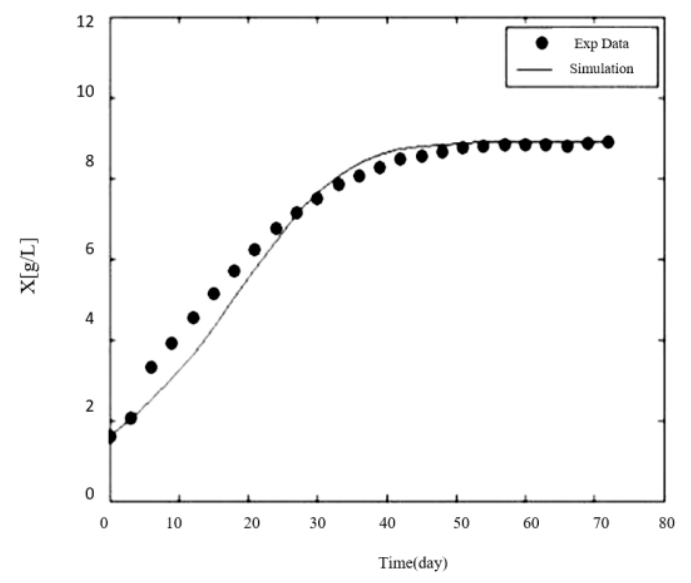

Figure 2. Variation of microorganisms' concentration with time.

From the comparison between the obtained results and the reference laboratory results [20-22], it is clear that the modeling can be used to predict the amount of methane production from animal waste and waste with good accuracy. The average relative error of the proposed model for predicting the amount of methane produced per day and laboratory results is $53.8 \%$. Due to the good agreement of laboratory data with the proposed model, the concentration of primary microorganisms on the amount of methane production in the reactor is investigated. Figure 4 shows the effect of microorganisms' initial concentration on the substrate's concentration over time. As shown from the figure, an increase in the initial concentration of microorganisms causes an increase in the substrate consumption rate. This allows the biogasproducing bacteria to directly enter the fermentation medium at the beginning of the process, and the decomposition process begins earlier. In other words, increasing the initial concentration of microorganisms accelerates the rate of decomposition of the input substrate, so if microorganisms are not used, or their initial concentration decreases, it takes time for the microorganisms to produce until the substrate decomposes and biogas is produced. This time is called the delay stage $[18,23]$. According to Figure 4 , as the initial concentration of microorganisms decreases, the latency phase increases.

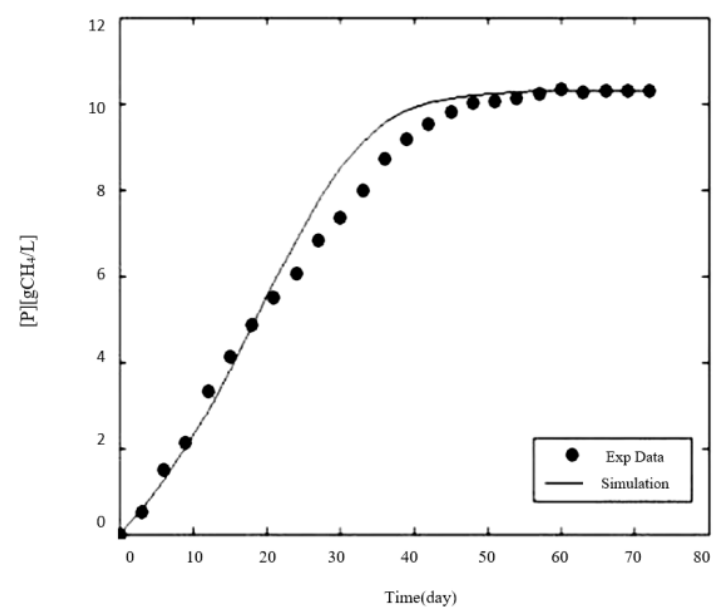

Figure 3. Methane concentration versus time. 


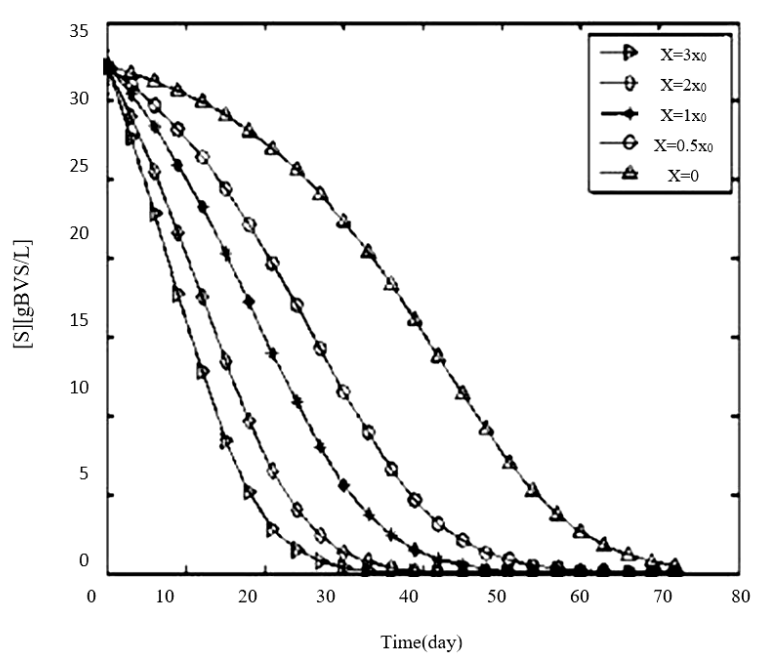

Figure 4. Variation of inlet substrate concentration with time at a different load of microorganisms.

According to Figure 5, as the initial concentration of microorganisms increases, the growth rate of microorganisms increases, and as a result, the input substrate decomposes faster. Therefore, it can be expected that by increasing the initial concentration of microorganisms, the production of the final product can is done in less time. As shown in Figure 5, the growth of microorganisms can be divided into four stages. For example, for the concentration $\mathrm{X}=\mathrm{X}_{0}=0$, the following conditions are true:

- The delay stage is approximately from zero to 9 days.

- The exponential stage $[1,24]$ in which microorganisms' growth is exponential is from day 9 to 57 .

- The growth rate phase $[5,25]$ is exactly after the exponential phase and is from day 57 to 63.

- Stagnation stage $[11,26]$ in which microorganisms' growth is proven and starts from day 63 onwards.

Figure 5 shows that as the initial concentration of microorganisms decreases, the latency phase increases and the growth rate decreases, and the stagnation phase is delayed. While increasing the concentration of microorganisms has exactly the opposite effect.

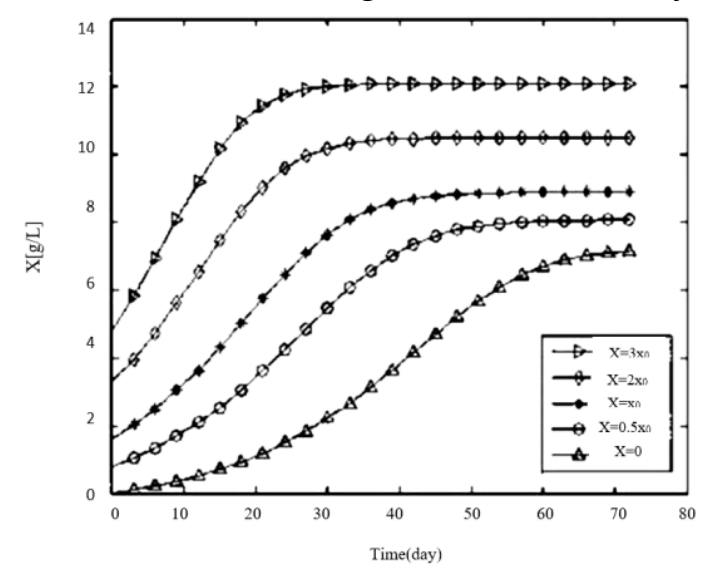

Figure 5. The effect of a different load of microorganisms on microorganisms' concentration

Figure 6 shows that increasing the initial concentration of microorganisms by reducing the delay phase and increasing the exponential phase's slope has increased methane gas production. At all concentrations used, the quiescent phase has a certain value. The inert gas concentration is $29.10 \mathrm{~g} / \mathrm{L}$. Therefore, it can be seen that the maximum biogas produced is a 
certain amount and depends on the amount of input substrate. Increasing the concentration of microorganisms by reducing the delay step accelerates the reaction and decomposition of the substrate.

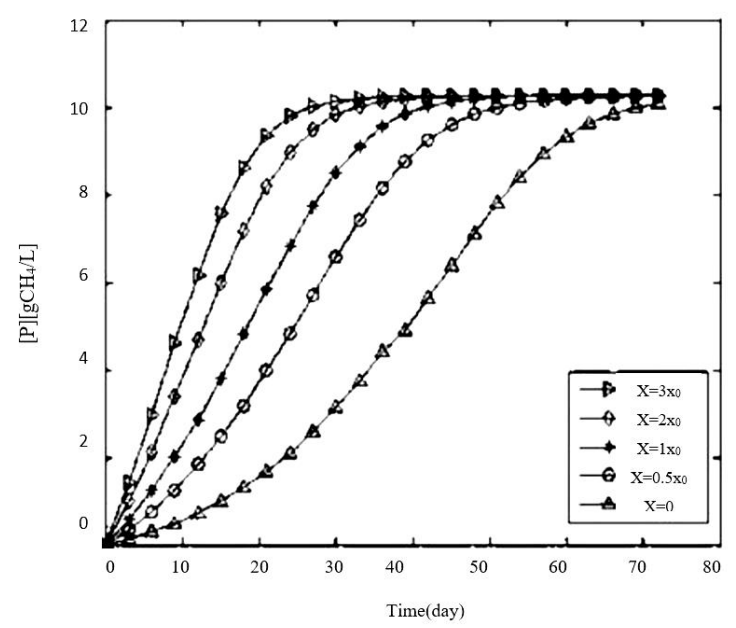

Figure 6. The effect of microorganism's load on methane produced convention.

\section{Conclusions}

Due to the need to use renewable energy, theoretical studies have been conducted in biogas production. Biogas production from plant wastes, fats, wastewater, etc., has been considered. Due to livestock manure's ability to produce biogas in this study, a continuous biogas production reactor from animal waste has been modeled and simulated. The digestion simulation of biogas production has been done using a simple kinetic model, and also, the conventional and simple Rong Kata method of order four has been used to solve the equations. However, the model results agree with the laboratory results of the biogas production process from animal waste. In this study, the effect of the initial concentration of microorganisms on methane production was investigated, and the following results were obtained. The equation of production speed of microorganisms is of the first degree. With the substrate's complete consumption, microorganisms' production also stops and reaches a constant amount. The decomposition rate of the substrate and methane gas production depends on the substrate's residence time. By increasing the initial concentration of microorganisms, the final product's production should be done in less time. Also, the delay stage is shorter, and consequently, the time required for complete decomposition of the input substrate is reduced. Change in the initial concentration of microorganisms does not change the final product's production and only accelerates the substrate's fermentation, increases the speed of biogas production, and reduces the time to reach its maximum concentration. In other words, the primary microorganisms act as catalysts. Therefore, it can be said that the biogas production reaction from animal waste is autocatalytic.

\section{Funding}

This research received no external funding.

\section{Acknowledgments}

Authors thank the scientific supports of Amirkabir university of technology. 


\section{Conflicts of Interest}

The authors declare no conflict of interest.

\section{References}

1. Holder, N.; Persaud, A.; Mota-Meira, M.; Born, J.; Sutrina, S.L. The influence of physico-chemical parameters, substrate concentration, and species variations on the biochemical methane production rates of ten tropical/subtropical grasses. Biofuels, Bioproducts and Biorefining 2019, 13, 21-36, https://doi.org/10.1002/bbb.1942.

2. Holder, N.; Mota-Meira, M.; Born, J.; Sutrina, S.L. Bio-Methane Production via Anaerobic Co-Digestion by Optimizing the Mixing Ratios of River Tamarind (Leucaena leucocephala) and Dolphin Fish (Coryphaena hippurus) Offal. Processes 2020, 8, https://doi.org/10.3390/pr8080934.

3. Lanzillo, F.; Ruggiero, G.; Raganati, F.; Russo, M.E.; Marzocchella, A. Batch Syngas Fermentation by Clostridium carboxidivorans for Production of Acids and Alcohols. Processes 2020, 8, https://doi.org/10.3390/pr8091075.

4. Ugwu, C.C.; Hair-Bejo, M.; Nurulfiza, M.I.; Omar, A.R.; Ideris, A. Propagation and Molecular Characterization of Fowl Adenovirus Serotype 8b Isolates in Chicken Embryo Liver Cells Adapted on Cytodex $^{\mathrm{TM}} 1$ Microcarrier Using Stirred Tank Bioreactor. Processes 2020, 8 , https://doi.org/10.3390/pr8091065.

5. Ramírez, L.A.; Pérez, E.L.; García Díaz, C.; Camacho Luengas, D.A.; Ratkovich, N.; Reyes, L.H. CFD and Experimental Characterization of a Bioreactor: Analysis via Power Curve, Flow Patterns and k L a. Processes 2020, 8, https://doi.org/10.3390/pr8070878.

6. Ebrahimi, M.; Tamer, M.; Villegas, R.M.; Chiappetta, A.; Ein-Mozaffari, F. Application of CFD to Analyze the Hydrodynamic Behaviour of a Bioreactor with a Double Impeller. Processes 2019, 7, https://doi.org/10.3390/pr7100694.

7. Formánek, R.; Šulc, R. The Liquid-Liquid Dispersion Homogeneity in a Vessel Agitated by a High-Shear Sawtooth Impeller. Processes 2020, 8, https://doi.org/10.3390/pr8091012.

8. de la Morena, S.; Wojtusik, M.; Santos, V.E.; Garcia-Ochoa, F. Kinetic Modeling of Dihydroxyacetone Production from Glycerol by Gluconobacter oxydans ATCC 621 Resting Cells: Effect of Fluid Dynamics Conditions. Catalysts 2020, 10, https://doi.org/10.3390/catal10010101.

9. Liu, K.; Phillips, J.R.; Sun, X.; Mohammad, S.; Huhnke, R.L.; Atiyeh, H.K. Investigation and Modeling of Gas-Liquid Mass Transfer in a Sparged and Non-Sparged Continuous Stirred Tank Reactor with Potential Application in Syngas Fermentation. Fermentation 2019, 5, https://doi.org/10.3390/fermentation5030075.

10. Li, Y.; Zhang, Y.; Wang, X.Z. Secondary Nucleation Kinetics of AIBN Crystallisation in Methanol: Online Imaging-Based Measurement and Modelling. Crystals 2020, 10, https://doi.org/10.3390/cryst10060506.

11. Stasiak-Różańska, L.; Berthold-Pluta, A.; Dikshit, P.K. Valorization of Waste Glycerol to Dihydroxyacetone with Biocatalysts Obtained from Gluconobacter oxydans. Applied Sciences 2018, 8, https://doi.org/10.3390/app8122517.

12. Carpine, R.; Olivieri, G.; Hellingwerf, K.J.; Pollio, A.; Marzocchella, A. Industrial Production of Poly- $\beta-$ hydroxybutyrate from CO2: Can Cyanobacteria Meet this Challenge? Processes 2020, 8, https://doi.org/10.3390/pr8030323.

13. Galvanauskas, V.; Simutis, R.; Levišauskas, D.; Urniežius, R. Practical Solutions for Specific Growth Rate Control Systems in Industrial Bioreactors. Processes 2019, 7, https://doi.org/10.3390/pr7100693.

14. Hans, S.; Haby, B.; Krausch, N.; Barz, T.; Neubauer, P.; Cruz-Bournazou, M.N. Automated Conditional Screening of Multiple Escherichia coli Strains in Parallel Adaptive Fed-Batch Cultivations. Bioengineering 2020, 7, https://doi.org/10.3390/bioengineering7040145.

15. Vandermies, M.; Fickers, P. Bioreactor-Scale Strategies for the Production of Recombinant Protein in the Yeast Yarrowia lipolytica. Microorganisms 2019, 7, https://doi.org/10.3390/microorganisms7020040.

16. Fickers, P.; Cheng, H.; Sze Ki Lin, C. Sugar Alcohols and Organic Acids Synthesis in Yarrowia lipolytica: Where Are We? Microorganisms 2020, 8, https://doi.org/10.3390/microorganisms8040574.

17. Vieira Gomes, A.M.; Souza Carmo, T.; Silva Carvalho, L.; Mendonça Bahia, F.; Parachin, N.S. Comparison of Yeasts as Hosts for Recombinant Protein Production. Microorganisms 2018, 6, https://doi.org/10.3390/microorganisms6020038. 
18. Park, Y.-K.; Nicaud, J.-M. Metabolic Engineering for Unusual Lipid Production in Yarrowia lipolytica. Microorganisms 2020, 8, https://doi.org/10.3390/microorganisms8121937.

19. Do, D.T.H.; Theron, C.W.; Fickers, P. Organic Wastes as Feedstocks for Non-Conventional Yeast-Based Bioprocesses. Microorganisms 2019, 7, https://doi.org/10.3390/microorganisms7080229.

20. Papanikolaou, S.; Diamantopoulou, P.; Blanchard, F.; Lambrinea, E.; Chevalot, I.; Stoforos, N.G.; Rondags, E. Physiological Characterization of a Novel Wild-Type Yarrowia lipolytica Strain Grown on Glycerol: Effects of Cultivation Conditions and Mode on Polyols and Citric Acid Production. Applied Sciences 2020, 10, https://doi.org/10.3390/app10207373.

21. Norouzi, N.; Hosseinpour, M.; Talebi, S.; Fani, M. A 4E analysis of renewable formic acid synthesis from the electrochemical reduction of carbon dioxide and water: studying impacts of the anolyte material on the performance of the process. Journal of Cleaner Production 2021, 293, 126149, https://doi.org/10.1016/j.jclepro.2021.126149.

22. Khajehpour, H.; Norouzi, N.; Shiva, N.; Folourdi, R.M.; Bahremani, E.H. Exergy Analysis and Optimization of Natural Gas Liquids Recovery Unit. International Journal of Air-Conditioning and Refrigeration 2020, https://doi.org/10.1142/s201013252150005x.

23. Fani, M.; Norouzi, N.; Ramezani, M. Energy, Exergy, and Exergoeconomic Analysis of Solar Thermal Power Plant Hybrid with Designed PCM Storage. International Journal of Air-Conditioning and Refrigeration 2020, 28, 2050030, https://doi.org/10.1142/S2010132520500303.

24. Norouzi, N.; Talebi, S.; Najafi, P. Thermal-hydraulic efficiency of a modular reactor power plant by using the second law of thermodynamic. Ann. Nucl. Energy 2021, 151, 107936, https://doi.org/10.1016/j.anucene.2020.107936.

25. Norouzi, N. The Pahlev Reliability Index: A measurement for the resilience of power generation technologies versus climate change. Nuclear Engineering and Technology 2020, https://doi.org/10.1016/j.net.2020.10.013.

26. Norouzi, N.; Fani, M.; Talebi, S. Exergetic design and analysis of a nuclear SMR reactor tetrageneration (combined water, heat, power, and chemicals) with designed PCM energy storage and a CO2 gas turbine inner cycle. Nuclear Engineering and Technology 2021, 53, 677-687, https://doi.org/10.1016/j.net.2020.07.007. 